
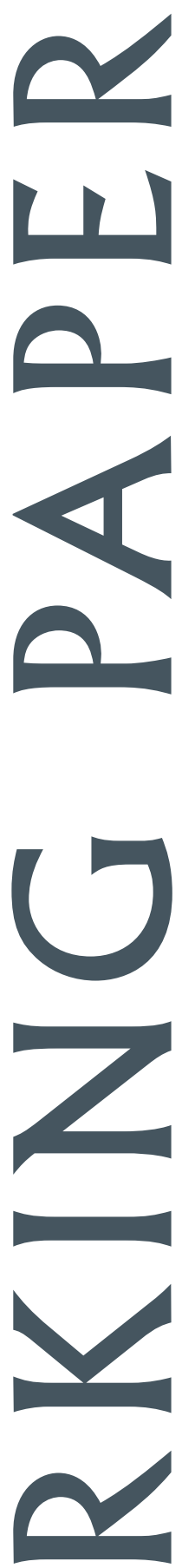

EAST-WEST CENTER 
The East-West Center is an education and research organization established by the U.S. Congress in 1960 to strengthen relations and understanding among the peoples and nations of Asia, the Pacific, and the United States. The Center contributes to a peaceful, prosperous, and just Asia Pacific community by serving as a vigorous hub for cooperative research, education, and dialogue on critical issues of common concern to the Asia Pacific region and the United States. Funding for the Center comes from the U.S. government, with additional support provided by private agencies, individuals, foundations, corporations, and the governments of the region.

East-West Center Working Papers are circulated for comment and to inform interested colleagues about work in progress at the Center.

For more information about the Center or to order publications, contact:

Publication Sales Office

East-West Center

1601 East-West Road

Honolulu, Hawai'i 96848-1601

Telephone: 808.944.7145

Facsimile: 808.944.7376

Email: ewcbooks@EastWestCenter.org

Website: www.EastWestCenter.org 


\title{
In What Format and Under What Timeframe Would China Take on Climate Commitments? A Roadmap to 2050
}

\author{
ZhongXiang Zhang
}

ZhongXiang Zhang is a Senior Fellow in the Research Program at the East-West Center. Currently, he is a co-editor of International Journal of Ecological Economics and Statistics, and serves on the editorial boards of seven leading international journals (Climate Policy; Energy Policy; Energy and Environment; Environmental Science and Policy; International Environmental Agreements; Mitigation and Adaptation Strategies for Global Change; Scientific World Journal) and one Chinese journal (Journal of Environmental Economics and Policy). Eleven of his publications are cited by IPCC Climate Change 2001: Mitigation and IPCC Climate Change 2007: Mitigation of Climate Change, making him one of the most cited authors in that two comprehensive and authoritiative publications of mitigating climate change and the associated costs.

Prepared for International Environmental Agreements: Politics, Law and Economics, Springer, Special Issue (Guest Edited by Carlo Carraro and Emanuele Massetti) on Reconciling Domestic Energy Needs and Global Climate Policy: Challenges and Opportunities for China and India.

East-West Center Working Papers: Environmental Change, Vulnerability, and Governance Series is an unreviewed and unedited prepublication series reporting on research in progress. The views expressed are those of the authors and not necessarily those of the Center. Please direct orders and requests to the East-West Center's Publication Sales Office. The price for Working Papers is $\$ 3.00$ each plus shipping and handling. 
This version: June 2, 2009

\title{
In What Format and under What Timeframe Would China Take on Climate Commitments? A Roadmap to 2050 ${ }^{1}$
}

\author{
ZhongXiang Zhang, Ph.D in Economics \\ 张中祥 美国东西方中心研究部资深㸴究员、经济学博士 \\ Senior Fellow \\ Research Program \\ East-West Center \\ 1601 East-West Road \\ Honolulu, HI 96848-1601 \\ United States \\ Tel: $+1-808-9447265$ \\ Fax: +1-808-944 7298 \\ Email: ZhangZ@EastWestCenter.org
}

\begin{abstract}
Given that China is already the world's largest carbon emitter and its emissions continue to rise rapidly in line with its industrialization and urbanization, there is no disagreement that China eventually needs to take on binding greenhouse gas emissions caps. However, the key challenges are when that would occur and what credible interim targets China would need to take on during this transition period. This paper takes these challenges by mapping out the roadmap for China's specific commitments towards 2050. Specifically, I suggest that China make credible quantified domestic commitments during the second commitment period, commit to voluntary no lose targets during the third commitment period, adopt binding carbon intensity targets during the fourth commitment period, and take on binding emissions caps starting the fifth commitment period and aimed for the global convergence of per capita emissions by 2050. These proposed commitments should be viewed as China's political commitments, not necessarily China's actual takings in the ongoing international climate change negotiations, in order to break the current political impasse between developed and developing countries. It is worthwhile China considering these political commitments either on its own or through a joint statement with U.S. and other major countries, provided that a number of conditions can be worked out. These commitments are principles, and still leave flexibility for China to work out details as international climate change negotiations move on. But in the
\end{abstract}

\footnotetext{
${ }^{1}$ Prepared for International Environmental Agreements: Politics, Law and Economics, Springer, Special Issue (Guest Edited by Carlo Carraro and Emanuele Massetti) on Reconciling Domestic Energy Needs and Global Climate Policy: Challenges and Opportunities for China and India. The views expressed here are those of the author, and do not reflect the positions of his affiliations. The author bears sole responsibility for any errors and omissions that may remain.
} 
meantime, they signal well ahead that China is seriously committed to addressing climate change issues, alleviate, if not completely remove, U.S. and other industrialized country's concerns about when China would get in, an indication that the whole world has long awaited from China, help U.S. to take on long-expected emissions commitments, and thus pave the way for reaching an international climate agreement at Copenhagen.

JEL classification: Q42; Q48; Q52; Q54; Q58

Keywords: Carbon intensity target; Binding emissions caps; Post-Kyoto climate negotiations; Energy saving; Renewable energy; Clean development mechanism; China; USA; India

\section{Introduction}

In addressing climate change issues, China and India are always put together as the big emerging economies. There are similarities between the two most populous countries, but there exist substantial differences between them. Such differences imply that China needs to come prepared to take on even more stringent greenhouse gas emission commitments and correspondingly to bear the higher compliance costs than India does. Let me to explain why.

Both China and India heavily rely on coal to fuel their economies, but coal accounts for a much larger share in China's energy mix than that of India. As the world's largest coal producer and consumer, China produces and consumes about twice as much coal as the U.S., the world's second largest producer and consumer. Coal has accounted for over two-thirds of China's primary energy consumptions for several decades. Coal-fired power plants dominate total electricity generation in China, consuming over half of the total coal use. As a result, China's total installed capacity of coal-fired power plants is more than the current total of the U.S., the United Kingdom and India combined.

Both countries have experienced spectacular economic growth over the past two decades, but China has grown and is projected to continue to grow faster than India for quite some time to follow. Economic structure differs significantly between the two countries. In comparison with other countries at its income level, China has an unusually large share of energy-intensive industrial production and an unusually small share of less energyintensive service sector. For example, 48\% of China's GDP in 2006 originated from the industry sector and $40 \%$ from the service sector, while the corresponding figures for India are $28 \%$ and 55\%, respectively. Moreover, the differing composition of industry affects the levels of energy intensity. China has a larger share of energy-intensive manufacturing in industry than that in India, with manufacturing contributing to 33\% of China's GDP in 2006 relative to the corresponding 16\% for India (World Bank, 2008). Thus, China uses more energy per unit of industrial output, although the unit energy consumption for major industrial products in China is lower than in India (Zhang, 1995 and 1997). As the 
workshop of the world, a hefty chunk of China's emissions are embedded in goods that are produced for exports to industrialized countries.

China is the world's most populous country, and has experienced a very low rate of population growth through implementing its strict family control programs. By contrast, the world's second most populous country grows at a much higher rate than China does, and is expected to take over China before 2030 (UNDESA, 2009). ${ }^{2}$

All the factors combined lead to that both China's total and per capita greenhouse gas emissions are much higher than India's. This gap between China's per capita $\mathrm{CO}_{2}$ emissions and India's is projected to even widen in the future. By 2030, China's per capita carbon emissions are projected to be well above the world's average under the business as usual scenario, whereas the corresponding India's are expected to be below the world's average. The Indian Climate Change Ambassador Shyam Saran was quoted as saying that "India is not at the same level as China". Saran argued that simply categorizing India as the world's third largest emitter "masks the fact that between No. 1, No. 2 and No. 3, there is a huge gap" (ClimateWire, 2009). India proposed basing future commitments on per capita emissions. This would potentially lead to differentiation between China and India and among developing countries because China would fall into a more demanding emission reduction category than India. So, if both countries were required to cut their emission levels to the world's average on a per capita basis, then China would experience higher compliance cost than India.

Indeed, If China's energy use and the resulting carbon emissions had followed their trends between 2000 and 2020, during which China achieved a quadrupling of its GDP with only a doubling of energy consumption, rather than surged since 2001, then international climate debate on China would now be much different. On the trends in the 1980s and 1990s, the U.S. EIA estimated that China's $\mathrm{CO}_{2}$ emissions are not expected to catch up with the world's largest carbon emitter by 2030 (EIA, 2003). However, China's energy use had surged since the turn of this century, almost doubling between 2000 and 2007. Despite similar rates of economic growth, the rate of growth in China's energy use during this period (9.74\% per year) has been more than twice that of the last two decades in the past century (4.25\% per year) (National Bureau of Statistics of China, 2008). This is mainly because China is still in the course of rapid industrialization and urbanization, which in turn requires to consume energy to produce energy-intensive steels, cements, glasses etc for cars, buildings, houses and public infrastructures, and partly because China failed to keep the expansion of inefficient and highly polluting industries under control and to implement its own set industrial restructuring and sustainable development policies.

While China should take the main responsibilities for this, the U.S. factor has also played a role here. To see why, let us go back to international climate negotiations prior to Kyoto

\footnotetext{
${ }^{2}$ UNDESA (2009) projects that China's population would peak at 1462.5 millions around 2030, while India's population would be projected to be at 1484.6 millions in 2030 and further to grow to 1613.8 millions in 2050 .
} 
and subsequently until the U.S. withdrawal from the Kyoto Protocol. Prior to Kyoto, developing counties' demand for the U.S. to demonstrate the leadership and the EU proposal for a 15\% cut in emissions of a basket of three greenhouse gases below 1990 levels by 2010 put collective pressure on the U.S., which led the world in greenhouse gas emissions at that time. At Kyoto, the U.S. had made legally binding commitments. The Kyoto target is seen as not enough but yet not unreasonable given that the U.S. economy would not be disrupted unreasonably. This may give the U.S. some "moral” right to persuade developing countries to take meaningful mitigation action. After Kyoto, the ball was kicked into China's court. The U.S. had made it clear that bringing key developing countries, including China, on board had been and would continue to be its focus of international climate change negotiations. According to some U.S. Senators, it will be countries like China, India and Mexico that will decide whether the U.S. will ratify the Kyoto Protocol. It is therefore conceivable that the pressure will mount for China to make some kind of commitments at the negotiations subsequent to Buenos Aires. The world's media will undoubtedly bring attention to China's non-participation, which will be seen as holding up the ratification of the Protocol by the U.S. Senate and possibly even be blamed for "blowing up" subsequent negotiations aimed at dealing with developing countries' commitments. The U.S. commitments at Kyoto and diplomatic and public pressure on China had put China in a very uncomfortable position. ${ }^{3}$ It looked like China would be pressured to take on commitments at much earlier date than what China wished.

This situation changed once the U.S. withdrew from the Kyoto Protocol. The U.S. withdrawal from the Kyoto Protocol in 2001 not only led current U.S. emissions to be well above their 1990 levels and the world to lose 8 years of concerted efforts towards climate change mitigation and adaptation, but also removed international pressure on China to take climate change mitigation actions when the Chinese economy is growing rapidly. It is since 2001 that China reversed a decline trend in its energy intensity over the

\footnotetext{
${ }^{3}$ Under these circumstances and in anticipation that the U.S. would take on the more stringent commitments in the post-2012 period, I envisioned a decade ago the following six proposals that could be put on the table as China's plausible negotiation position. “First, China could regard its active participation in CDM as 'meaningful participation'. Second, China could commit to demonstrable efforts towards slowing its greenhouse gas emissions growth at some point between the first commitment period and 2020. Third, China could to make voluntary commitments to specific policies and measures to limit greenhouse gas emissions at some point between the first commitment period and 2020 . Policies and measures might need to be developed to explicitly demonstrate whether or not China has made adequate efforts. Fourth, China could make a voluntary commitment to total greenhouse gas emissions per unit of GDP at some point around or beyond 2020. The fifth option would be for China to voluntarily commit to an emissions cap on a particular sector at some point around or beyond 2020. Taking on such a commitment, although already burdensome for China, could raise the concern about the carbon leakage from the sector to those sectors whose emissions are not capped. This leads to the final option that China could offer: a combination of a targeted carbon intensity level with an emissions cap on a particular sector at some point around or beyond 2020.” (Zhang, 2000).
} 
last two decades in the past century, experiencing faster energy consumption than economic growth. It would be silly to blame this for the U.S., but if the U.S. would not withdraw from the Kyoto Protocol, for its own competiveness concerns alone the U.S. would keep pressuring on China just like it did immediately after Kyoto and is currently doing, China’s actual greenhouse emissions would be lower than its current levels.

After what is viewed as eight years of lost time under President Bush, the U.S. is now determined to fully engage with international community to seal a global deal to succeed the Kyoto Protocol late this year. However, as argued in Zhang (2009a), I seriously doubt that developing countries will go beyond the defined policies and measures before 2020 for several reasons.

First, given the very short timeframe to conclude the negotiations, it would be impossible, in all likelihood, to agree on the levels of ambitions for developing countries, on the countries and sectors covered, and on the specific rules, especially due to the amount of the data that would be required. Second, it is inconceivable that developing countries would ever go beyond the aforementioned third option between 2013 and 2020 without an effective financial mechanism. The pledged funding under the UNFCCC and its Kyoto Protocol represents only a small percentage of the anticipated mitigation and adaptation needs of developing countries (Zhang, 2009a). Unless this funding situation changes significantly, which is not likely to happen, developing countries cannot afford to make commitments beyond defined policies and measures. Third, the U.S. factor will continue to play a role in affecting developing countries' willingness to take on commitments and the stringency of these commitments. The U.S. House of Representatives Energy and Commerce Committee recently approved the American Clean Energy and Security Act of 2009 that would cut U.S. carbon emissions by 17\% from 2005 levels by 2020. Now this bill must proceed through several more committees, before it reaches the full House of Representatives for a final vote. It is uncertain whether it becomes law by the end of this year. Even if it became law, U.S. greenhouse gas emissions in 2020 would at best be kept at their 1990 level. This is far from the drastic cuts in emissions developing countries would expect before taking on their own commitments.

While it would be desirable if the U.S. could commit to a $25-40 \%$ cut as called for by developing countries, having the U.S. to commit quantified emissions cuts matters most to the Copenhagen talks, because the U.S. commitment to cut emissions is deemed essential to a global pact. Whether such commitments would timely emerge rests with the U.S. Congress. Understandably, in the course of debating and voting the aforementioned Waxman-Markey bill, the U.S. Congress will push for major emerging economies and even use the threat of trade measures, such as carbon tariffs, ${ }^{4}$ to induce developing economies, such as China and India, to go beyond the defined policies and measures as demonstrated when the U.S. Senate debated the Lieberman-Warner Climate Security Act in 2008. The senior officials under the Obama administration signal that the U.S. is not

\footnotetext{
${ }^{4}$ See Zhang (2008, 2009b) for further discussion on WTO scrutiny of the LiebermanWarner type of border adjustment provision.
} 
going to change its suggested emissions cuts for $2020,{ }^{5}$ which is far below what developing countries call for, claiming that that there is a little room. Similarly, there is a little room left for developing countries before 2020, although for reasons very different from those of the U.S.. Therefore, the key issue is post-2020, not pre-2020.

Not immediately but down the road, if China is persuaded to accept some kind of specific long-term commitments comparable to its development stage over time, that will send a clear signal to the U.S. Congress that China is seriously committed to addressing global climate change. That will reduce U.S. concerns about carbon leakages and competiveness, and boost domestic American support for tough climate actions. Consequently, that will help a passage of U.S. domestic climate bill and a ratification of a global new deal that would emerge at Copenhagen. Whether you like or not, the political reality is that, while U.S. commitment to cut emissions is essential to a global pact, how China is doing in that context is a crucial, if not decisive, factor in both determining the ambition of that commitment and taking on that commitment.

This paper is organized as follows. Section 2 discusses a realistic date on which China would be expected to take on absolute emissions caps. Section 3 envisions what kinds of credible interim targets we would expect China to take on during this transition period from the second commitment period to taking on binding emissions caps. Section 4 draws some concluding remarks.

\section{When would China be expected to take on absolute emissions caps?}

It is unlikely that China would go from rapid emissions growth to immediate emissions cuts without passing through an intermediate phase of slowing-then peaking before reserving. The key questions are: 1 ) a realistic date on which China would be expected to take on absolute emissions caps in a combination of China's own assessment and international pressure? and 2) what kinds of credible interim targets we would expect China to take on during this transition period from the second commitment period to taking on binding emissions caps? In this section, I focus on the first question. The next section will address the second one.

\section{Around 2030: the timing of China taking on absolute emissions caps}

The timing when China would take on absolute emissions caps needs to take many factors into consideration. I think the fifth commitment period (2028-2032), or around 2030 is not an unreasonably expected date on which China needs to take on absolute emissions caps. Understandably, 2030 is later than the U.S. and other industrialized

\footnotetext{
${ }^{5}$ U.S. Energy Secretary Steven Chu indicated that Washington was not interested in retooling its percentage goal for 2020. He was quoted as saying that "I think that rather than debating a few percent, the best thing we can do is to get started as soon as possible" (Reuters, 2009b). Todd Stern, U.S. Special Envoy for Climate Change, was quoted as saying that signing up for cuts of 25-40\% below 1990 levels by 2020 would be "a prescription not for progress, but for stalemate” in the U.S. Congress (ClimateWire, 2009).
} 
countries would like to see, but is not unreasonable. From China's perspective, it would probably be still too soon.

The fourth assessment report of the IPCC (2007) recommends that avoiding dangerous climate change consequences would require global greenhouse gas emissions to peak by 2020 as the latest and turn downwards afterwards. With China already being the world's largest carbon emitter (MNP, 2007; EIA, 2009), the earlier China would take on emissions caps, the more likely that goal would be achieved. So, Hu (2009) argues that China should mirror this global roadmap, and thus suggests that China's carbon emissions should have peaked by 2020 and be cut to their 1990 levels by 2030. However, given that China is a country at low development stage and has coal-fueled, rapidly growing economy, its carbon emissions are still on the climbing trajectories. The EIA (2009) projects China's baseline carbon emissions in 2020 to be 4.11 times their 1990 levels, and to be expected to continue to grow afterwards, climbing to 5.12 times their 1990 levels in 2030. While energy use in China is projected to grow somewhat slower in the 2020s than in the 2010s, non studies have projected that China's carbon emissions would peak by 2030, even if some energy saving policies and measures have been factored into such projections. It should thus come as no surprise that Hu's proposal has received very negative reactions from China's delegation to the United Nations conference on climate change. ${ }^{6}$

Even if 2020 is considered unrealistic, then what is a realistic date to expect China to take on emissions caps? It should be pointed out that before legally binding commitments become applicable to Annex I countries, they have a grace period of 16 years starting from the Earth Summit in June 1992 when Annex I countries promised to individually or jointly stabilize emissions of $\mathrm{CO}_{2}$ and other greenhouse gases at their 1990 levels by the end of the past century to the beginning of the first commitment period in 2008. This would point to the first binding commitment period starting around 2026 for China.

While it is not unreasonable to grant China a grace period, delaying the timing of China taking on emissions caps beyond 2030 is not acceptable. China is now already the world's largest carbon emitter and is about to take over Japan as the world's second largest economy this year or so, although its per capita income and emissions are still very low. With another twenty years of rapid development, China's economy becomes even close to the U.S., and its absolute emissions are well above the second largest

\footnotetext{
${ }^{6}$ One member of China delegation to the international conference on climate change at Bonn considered his suggestion "irresponsible utopian speeches", and wrote that "the author mentions none of China's relevant basic conditions in his speech about climate change problems. Instead he focuses on empty talk about international fairness and justice. The author lacks intrinsic knowledge about how climate change problems have appeared and lacks any common sense of history or knowledge of the current situation of international politics. Because of this, his conclusions could mislead readers, which is irresponsible and without vitality”. Available at:

http://www.chinadialogue.net/article/show/single/en/2892-A-new-approach-atCopenhagen-1-.
} 
emitter. The EIA (2009) projects that China's baseline carbon emissions in 2030 amount to 11.73 billion tons of carbon dioxide, relative to 6.4 billion tons for the U.S. This gap could become even bigger, provided that the U.S. would cut its emissions to the levels proposed by the Obama administration and under the American Clean Energy and Security Act of 2009. By then, China's per capita income will reach to the very reasonable level and its per capita emissions will be well above the world's average. The EIA (2009) puts the estimated per capita carbon emissions in 2030 at 8.05 tons of carbon dioxide for China, relative to the corresponding world's average of 4.85 tons of carbon dioxide. While the country is still on the climbing trajectory of carbon emissions under the business as usual scenario, China would have lost its ground not to take on emissions caps when the world faces ever alarming climate change threats and developed countries have demonstrated significant emissions reductions by then.

What about the transition period to 2030? Developing countries need reasonable time to develop and operate national climate policies and measures. Many studies point out the structural limitations of CDM, and suggest that if developing countries would take on sectoral or absolute emissions caps, then that will move the CDM from a project-based mechanism to a wholesale mechanism and allows developing countries to sell emission permits at the same world market price as developed countries whose emissions are capped, relative to the lower prices that developing countries have received for carbon credits generated from CDM projects. However, no institutional and infrastructure supports exist in the majority of developing countries for operating emissions trading. Developing countries including China need time to develop and operate such a scheme. Take the establishment of an emissions trading scheme as a case. Even for the U.S. $\mathrm{SO}_{2}$ Allowance Trading Program, the entire process from the U.S. Environmental Protection Agency beginning to compile the data for its allocation database in 1989 to publishing its final allowance allocations in March 2003 took almost four years. For the first phase of the EU Emissions Trading Scheme, the entire process took almost two years from the EU publishing the Directive establishing a scheme for greenhouse gas emission allowance trading on 23 July 2003 to it approving the last national allocation plan for Greece on 20 June 2005. For developing countries with very weak environmental institutions and that do not have dependable data on emissions, fuel uses and outputs for installations, this allocation process is expected to take much longer than what experienced in the U.S. and the EU and put a trading scheme into operation (Zhang, 2007a). That is the reason why I suggest to have voluntary no lose targets during the third commitment period (20182022), instead of immediately having such targets during the second commitment period. That will leave some time for developing countries to design and implement an emissions trading scheme which economists argue that developing countries would benefit from.

Another timing indicator is a lag between treaty signing and budget period. With the Kyoto Protocol signing in December 1997 and the first budget period staring 2008, the earliest date to expect China to introduce binding commitments is 2020. Even without the precedent for Annex I countries, China's demand is by no means without foundation. For example, the Montreal Protocol on Substances that Deplete the Ozone Layer grants developing countries a grace period of 10 years (Zhang, 2000). Given that the scope of economic activities affected by a climate regime is several orders of magnitude larger 
than those covered by the Montreal Protocol, in my view, there should be a grace period of much longer than 10 years for developing countries after mandatory emission targets for Annex I countries take effect. In the meantime, absolute emissions caps on developing countries need to be markedly below their baseline levels by 2030. We think that one way to ensure this is China committing to binding carbon intensity targets during the fourth commitment period (2023-2027).

\section{A Roadmap for China to 2050}

In what follows, I will discuss in what format and under what timeframe China would be included in a post-2012 climate change regime. I envision that China would need the three transitional commitment periods of increasing climate obligations before taking on absolute emissions caps.

\section{Credible quantified domestic commitments during the second commitment period}

China has already committed itself to quantified targets on energy saving and the use of clean energy (Zhang, 2009c), and has got credit for such efforts. ${ }^{7}$ China should extend its level of ambition, further making credible quantified domestic commitments to energy saving and the use of clean energy for the second commitment period. Such commitments include but are not limited to continuing to set energy-saving and pollutant control goals in the subsequent national five-year economic blueprints as challenging as the current 11th five-year (2006-2010) blueprint does, increasing investment in energy conservation and improving energy efficiency, significantly scaling up the use of renewable energies and other low-carbon technologies, in particular wind power and nuclear power, and providing additional support policies to accomplish its own ambitious energy-saving and clean energy goals. Currently, China has set to decommission thousands of small, inefficient coal-fired power plants with a unit capacity of $50 \mathrm{MW}$ or less. To the benefits of energy saving and the environment, China should consider doubling that unit capacity to 100 MW below which coal-fired plants need to be decommissioned (Zhang, 2009c).

Calling future goal as challenging as the current one requires to establish why the current $20 \%$ energy saving goal is considered very challenging. China sets the goal of cutting energy use per unit of GDP by $20 \%$ by 2010, relative to its 2005 level. In 2006, the first year of this energy efficiency drive, while China reversed a rise in its energy intensity in the first half of that year, the energy intensity only declined by $1.79 \%$ over the entire year. Although this decline is for the first time since 2003, it is far short of the target of $4 \%$. Among the 31 Chinese provinces or equivalent, only Beijing met that energy-saving goal in 2006, cutting its energy use per unit of GDP by $5.25 \%$, followed by Tianjin with the energy intensity reduction of 3.98\%, Shanghai by $3.71 \%$, Zhejiang by $3.52 \%$ and Jiangsu by $3.50 \%$ (NBS et al., 2007). ${ }^{8}$ In 2007, despite concerted efforts towards energy

\footnotetext{
${ }^{7}$ Todd Stern, U.S. Special Envoy for Climate Change, was quoted as saying that "The Chinese are doing a lot already, ... The Chinese have a lot of policy that they have put in place” (Reuters, 2009a).

${ }^{8}$ Beijing is the first provincial region in China to establish in 2006 the bulletin system to release data on energy use and water use per unit of GDP, quarterly releasing these and
} 
saving, the country cut its energy intensity by 3.66\%. There are still big variations in energy-saving performance among the 31 Chinese provinces or equivalent. Beijing still took the lead, cutting its energy intensity by $6 \%$, followed by Tianjin by $4.9 \%$ and Shanghai by $4.66 \%$ (NBS et al., 2008). This clearly indicated the Beijing's commitments to the 2008 Green Olympic Games. In the meantime, there were 7 provinces whose energy-saving performances were below the national average. With the country's overall performance of the first two years, to meet that national energy intensity target would need the energy intensity reduction averaging 5.44\% for each of the remaining three years. This required energy saving rate is even higher than the annual saving rate of $5.25 \%$ during the period 1980-2000 in which China achieved a quadrupling of its GDP while cutting its energy intensity by about three quarters (Zhang, 2003). Achieving that rate will certainly not be easy, if not absolutely impossible.

\section{Voluntary no lose targets during the third commitment period}

During the third commitment period (2018-2022), China could commit to adopting voluntary no lose targets. Such targets are defined as certain percentages of reduction from the country's business as usual emissions. Emissions reductions achieved beyond the no lose targets would then be eligible for sale. That will allow China to sell emission permits at the same world market price as developed countries whose emissions are capped, relative to the lower prices that China has currently received for carbon credits generated from CDM projects.

The keys to operate this option involve setting both baseline emissions and no lose targets. To avoid inflating baseline emissions, baselines must be generated by an independent international expert body, not by the Chinese national authority. ${ }^{9}$ On setting no lose targets, one option is to take the IPCC (2007) recommendation as a reference, which suggests that developing countries as a group will need to limit their greenhouse gas emissions to $15-30 \%$ below their baselines by 2020. Another option is based on China's own set energy or carbon intensity targets, which are then translated into the amount of emissions reductions from the baselines. Because having some quantitative targets is more critical than targets themselves, the no lose targets for China will be set not to exceed the higher of the above two alternatives to encourage China to take on such targets.

What is the yardstick or bound on the energy intensity of the Chinese economy in 2020? Between 1980-2000, China's GDP quadrupled, but its energy consumption only doubled. China aims to achieve a quadrupling of its GDP with only a doubling of energy consumption between 2000 and 2020, with a 20\% cut in the energy intensity between 2006-2010 deemed a crucial step towards that goal. Assuming that China's economy grows at the annual average rate of $7 \%$ per year and China is able to limit the growth in energy use to half the growth rate of the economy between 2006-2020, then China's

other indicators by county. See Zhang (2007b and 2007c) for detailed discussion on why Beijing met but the country missed the energy-saving goals.

${ }^{9}$ Frankel (2009) also suggests to use an independent international expert body to set baseline emissions in his formulas for emission targets for all countries. 
energy use per unit of GDP would be cut by $40 \%$ by 2020, relative to its 2005 levels. This back of the envelope calculation implies the assumed energy elasticity of 0.5 between 2006 and 2020. While China were able to accomplish that during the last two decades of the past century, going ahead, we should not naturally expect a return to that level, given that China had experienced faster energy consumption than economic growth between 2001 and 2005 and, as discussed earlier, is encountering great difficulty in meeting its 20\% energy intensity (Zhang, 2005, 2007b,c and 2009c). Thus, a 40\% cut in China's energy intensity by 2020 relative to 2005 is considered as an upper bound on China's possible no lose energy intensity targets.

Moreover, reducing China's baseline emissions below the no lose targets set by either of the aforementioned two options involves not only abatement costs, but also the costs associated with measurement, reporting and verification requirements that are more complex, demanding and thus costly to comply with than China's own domestic requirements. For a huge developing country like China with very weak environmental institutions and that do not have dependable data on emissions, fuel uses and outputs for installations and all reports have to be in English for this purpose, such costs, which occur to ensure that all the emissions data are properly measured, reported and verified in an aim to generate economically valuable and environmentally-credible credits and thus to ensure that an international emissions trading scheme works properly, are not expected to be trivial. So, combined this with the above upper bound arguments, China could conceivably assume a no lose target less stronger than the one set by its domestic energy or carbon intensity targets.

\section{Binding carbon intensity targets during the fourth commitment period}

During the fourth commitment period (2023-2027), China could commit to adopting binding carbon intensity targets. This will be a significant step forward towards committing to absolute emissions caps during the subsequent commitment period. In my view, carbon intensity of the economy is preferred to energy intensity of the economy (i.e., total energy consumption per unit of GDP), because all the efforts towards shifting away from high-carbon energy are awarded by the former. The carbon intensity is set further downwards relative to the third commitment period.

\section{Binding emissions caps starting the fifth commitment period}

Being granted the three transition commitment periods, China would be expected to take on binding emissions caps starting the fifth commitment period. The exact caps will be a function of many factors. While it would be desirable if China could commit to stringent emissions caps, having China to commit quantified emissions cuts is more critical than its emissions caps themselves because that will hold China's emissions on a contraction path. In my view, there is no need to worry too much about that emissions caps, given that actions to honor the interim targets during the transition periods would have driven China's emissions substantially below their business as usual levels. Thus, that emissions caps, no matter what value would be set eventually, would be substantially deviated from China's projected baseline emissions. Moreover, the caps should be set in such a way to aim for the global convergence of per capita emissions by 2050 as recommended by Stern 
(2008). ${ }^{10}$ Provided that the world would agree on this, it will serve as another way for China to carefully set its emissions caps from the fifth commitment period onwards in order to avoid overshooting the caps set based on the world's per capita emissions in 2050.

\section{Concluding remarks}

Countries from around the world are scheduled to meet in Copenhagen in December 2009 to try to hammer out a new post-2012 regime for attacking climate change problems. No one would disagree the U.S. commitment to cut emissions essential to such a global pact and President Obama's desire to lead after what is viewed as eight years of lost time under President Bush. However, much of Obama's ability to move forward in international climate negotiations rests with the U.S. Congress, because the Obama administration will likely be in the position to agree to a specific emission target that the whole world has long awaited only when the Congress has enacted or is on the verge of enacting a legislation capping the U.S. greenhouse gas emissions. The influential U.S. congressmen have frequently stressed the importance of China in helping a passage of U.S. domestic, carbon-constrained legislation and a ratification of a global new deal that would emerge at Copenhagen. Whether you like it or not, this is a political reality.

However, both sides see a little room before 2020, although for reasons very different from each other. Therefore, the key issue is post-2020, not pre-2020. With the U.S. aimed to cut its greenhouse gas emissions by $83 \%$ from their 2005 levels by 2050, what matters most now is U.S. taking on quantified emissions cuts immediately staring the second commitment period. The U.S. is unlikely to do that until China is politically willing to agree to some measurable, verifiable and reportable goals for greenhouse gas obligations. China is also expected to face increasing pressure from the European Union, who will find it increasingly hard to convince its citizens in general and the companies in particular why the EU has taken the lead but don't see China to follow. In my view, this is not the illegitimate concern, and overall competitiveness concerns mean that no country is likely to step out too far in front (Zhang, 2004). That goals that would meet U.S. expectations and at the same time, are considered acceptable by China are an open question. But the bottom line is that what that goals or obligations would be needs to fully respect China's rights to grow, and should reflect China's growing responsibility for emitting greenhouse gas emissions as the living of standards increases over time. After all, China is a developing country right now, no matter how rapidly the Chinese economy is expected to grow in the future. On the other hand, China is already the world's largest carbon emitter and its emissions continue to rise rapidly in line with its industrialization and urbanization. China needs to act as a large and responsible developing country and take due responsibilities and to set a good example to the majority of developing countries.

There is no disagreement that China eventually needs to take on binding greenhouse gas emissions caps. However, the key challenges are when that would occur and what credible interim targets China would need to take on during this transition period. No

${ }^{10}$ This does not necessarily means that I agree with Stern's suggested value of the global per capita emissions in 2050. 
doubt, that will result in a combination of China's own assessment of responsibility, economic and political benefits and of climate change impacts, the give and take of international negotiations, and mounting diplomatic and international pressure. Based on my educated judgments, this paper maps out the roadmap for China's specific commitments towards 2050. Specifically, I suggest that China make credible quantified domestic commitments during the second commitment period, commit to voluntary no lose targets during the third commitment period, adopt binding carbon intensity targets during the fourth commitment period, and take on binding emissions caps starting the fifth commitment period and aimed for the global convergence of per capita emissions by 2050. With China having very little responsibility for the current climate change problems and taking on commitments substantially deviated from its projected baseline emissions much earlier than what would have otherwise been, the U.S., the world's richest country and historically largest emitter, has no reason at all not to take on quantified emissions cuts immediately staring the second commitment period and to commit further stiff cuts by 2050 .

The proposed commitments should be viewed as China's political commitments, not necessarily China's actual takings in the ongoing international climate change negotiations, in order to break the current political impasse between developed and developing countries. They act much like the U.S. presidential campaign commitments which are subject to many factors to honor. China would make the proposed political commitments conditional on U.S. (and other industrialized countries) commitments to immediately taking on quantified emissions cuts and further stiff cuts by 2050, not to using the threat of trade or trade measures to China's products in U.S. approving or ratifying any bills, regardless of which are climate-related or international climate change agreements until around 2030, and on not expecting/forcing China to change the type and timing of commitments as outlined in my proposal. If that can be worked out, then I think that it is worthwhile China considering these outlined political commitments either on its own or through a joint statement with U.S. and other major countries. After all, these commitments are principles, and they still leave flexibility for China to work out details as international climate change negotiations move on. But in the meantime, they signal well ahead that China is seriously committed to addressing climate change issues, alleviate, if not completely remove, U.S. and other industrialized country's concerns about when China would get in, an indication that the whole world has long awaited from China, help U.S. to take on long-expected emissions commitments, and thus pave the way for reaching an international climate agreement at Copenhagen.

Finally, it should be pointed out that the value of my proposal is in what format and under what timeframe China would be included in a post-2012 climate change regime, not the details of particular numerical numbers. China taking on such increasingly stringent commitments should not be taken as granted because that requires China to take significant efforts towards cutting its projected emissions below the baselines. Political reality may limit the U.S. ability to take on significant emissions cuts by 2020 as developing countries called for, but as a tradeoff, the U.S. should significantly scale up its technology transfer and deployment, financing and capacity building to enable China to do that. This is at least what the U.S. can and should do, and by example can encourage 
other developed counties to do the same. As Winston Churchill said, "[you] can always count on the Americans to do the right thing - after exhausting every other alternative.”. After what is viewed as eight years of lost time, the whole world bets that U.S. will not disappoint us this time. Only history will tell us whether that will be a case.

\section{References}

ClimateWire (2009), India Rejects Comparison with China’s Emissions, March 26.

Department of Economic and Social Affairs of the United Nations (UNDESA, 2009), World Population Prospects: The 2008 Revision, Available at: http://esa.un.org/unpp.

EIA (2003), International Energy Outlook 2003, DOE/EIA0484(2003), U.S. Energy Information Administration (EIA), Washington, DC.

EIA (2009), International Energy Outlook 2009, DOE/EIA-0484(2009), U.S. Energy Information Administration (EIA), Washington, DC, May 27, Available at: http://www.eia.doe.gov/oiaf/ieo/.

Frankel, J.A. (2009), An Elaborated Global Climate Policy Architecture: Specific Formulas and Emission Targets for All Countries in All Decades, NBER Working Paper No. 14876, April, Available at: http://www.nber.org/papers/w14876.pdf.

Hu, A. (2009), A New Approach at Copenhagen, April 6, Available at: http://www.chinadialogue.net/article/show/single/en/2895-A-new-approach-atCopenhagen-2-.

Intergovernmental Panel on Climate Change (IPCC, 2007), Climate Change 2007: Mitigation of Climate Change, Working Group III Contribution to the Fourth Assessment Report, Cambridge University Press, Cambridge.

National Bureau of Statistics of China (2008), China Statistical Yearbook 2008, China Statistics Press, Beijing.

National Bureau of Statistic (NBS), National Development and Reform Commission and National Energy Administration (2008), Bulletin on Energy Use per Unit of GDP and other Indicators by Region, Beijing, July 14, Available at: http://www.stats.gov.cn/tjgb/qttjgb/qgqttjgb/t20080714_402491870.htm.

National Bureau of Statistic (NBS), National Development and Reform Commission and Office of The National Energy Leading Group (2007), Bulletin on Energy Use per Unit of GDP and other Indicators by Region, Beijing, July 12, Available at: http://hzs.ndrc.gov.cn/newjn/t20070809_152873.htm.

Netherlands Environmental Assessment Agency (MNP, 2007), China Now No. 1 in $\mathrm{CO}_{2}$ Emissions; USA in Second Position, June 19, Available at: 
http://www.mnp.nl/en/dossiers/Climatechange/moreinfo/Chinanowno1inCO2emissionsU SAinsecondposition.html.

Reuters (2009a), U.S. Praises China’s Climate Efforts; Urges More, March 29, Available at: http://www.reuters.com/article/environmentNews/idUSTRE52S1WP20090329.

Reuters (2009b), U.S. Seeks Reins in New Set of Climate Talks, April 24, Available at: http://www.reuters.com/article/environmentNews/idUSTRE53N12720090424.

Stern, N. (2008), Key Elements of a Global Deal on Climate Change, London School of Economics and Political Science, London, April, Available at:

http://www.lse.ac.uk/collections/granthamInstitute/publications/KeyElementsOfAGlobal Deal_30Apr08.pdf

World Bank (2008), World Development Indicators 2008, Washington, DC.

Zhang, Z.X. (1995), Energy Conservation in China: An International Perspective, Energy Policy, Vol. 23, No. 2, pp. 159-166.

Zhang, Z.X. (1997), The Economics of Energy Policy in China: Implications for Global Climate Change, New Horizons in Environmental Economics Series, Edward Elgar.

Zhang, Z.X. (2000), Can China Afford to Commit itself an Emissions Cap? An Economic and Political Analysis, Energy Economics, Vol. 22, No. 6, pp. 587-614.

Zhang, Z.X. (2003), Why Did the Energy Intensity Fall in China's Industrial Sector in the 1990s?, The Relative Importance of Structural Change and Intensity Change, Energy Economics, Vol. 25, No. 6, pp. 625-638.

Zhang, Z.X. (2004), Open Trade with the U.S. without Compromising Canada's Ability to Comply with its Kyoto Target, Journal of World Trade, Vol. 38, No. 1, pp. 155-182.

Zhang, Z.X. (2005), Sustainable Energy Development in China: Challenges Ahead to 2020, The Keynote Address at the International Conference on Staying Ahead of the Energy Scenarios, Bangkok, November 11.

Zhang, Z.X. (2007a), Why Has China not Embraced a Global Cap-and-Trade Regime?, Climate Policy, Vol. 7, No. 2, pp. 166-170.

Zhang, Z.X. (2007b), Greening China: Can Hu and Wen Turn a Test of their Leadership into a Legacy?, Presented at the Plenary Session on Sustainable Development at the firstever Harvard College China-India Development and Relations Symposium, New York City, March 30 - April 2. 
Zhang, Z.X. (2007c), Energy and Environmental Policy in Mainland China, The Keynote Address at the Cross-Straits Conference on Energy Economics and Policy, Organized by the Chinese Association for Energy Economics, Taipei, November 7-8.

Zhang, Z.X. (2008), Multilateral Trade Measures in a Post-2012 Climate Change Regime?: What Can Be Taken from the Montreal Protocol and the WTO?, Available at: http://papers.ssrn.com/sol3/papers.cfm?abstract_id=1328548.

Zhang, Z.X. (2009a), How Far Can Developing Country Commitments Go in an Immediate Post-2012 Climate Regime?, Energy Policy, Vol. 37, pp. 1753-1757.

Zhang, Z.X. (2009b), Encouraging Developing Country Involvement in a Post-2012 Climate Change Regime: Carrots, Sticks or Both?, in Trade and Climate Policies in a Post-2012 World, United Nations Environment Programme, Geneva, Switzerland.

Zhang, Z.X. (2009c), Is It Fair to Treat China as a Christmas Tree to Hang Everybody's Complaints? Putting its Own Energy Saving into Perspective, Energy Economics, doi:10.1016/S0140-9883(03)00042-2. 